\title{
ANALISIS KEMISKINAN DENGAN PENDEKATAN MODEL REGRESI SPASIAL DURBIN (Studi Kasus: Kabupaten Gianyar)
}

\author{
Luh Putu Safitri Pratiwi ${ }^{1}$, I Gusti Ayu Made Srinadi ${ }^{2}$, \\ MADE SUSILAWATI ${ }^{3}$ \\ 1,2,3 Jurusan Matematika FMIPA Universitas Udayana, Bukit Jimbaran-Bali \\ e-mail: ${ }^{1}$ safitri.pratiwi@yahoo.com, ${ }^{2}$ srinadiigustiayumade@yahoo.co.id, \\ ${ }^{3}$ susilawati.made@gmail.com
}

\begin{abstract}
Poverty still a complex problems for both at national and regional level, so it requires an appropriate and sustainable strategy mitigation. Every household in the different regions has different characteristics and influenced factors, so it requires the identification of the factors that influence poverty by paying attention to the influence of the area using the Spatial Durbin Model (SDM). The purpose of SDM modeling is to determine the spatial dependency relationship which occur not only in the dependent variables, but also on the independent variables. The result shows that the significant lagged dependent variable is indicated by the parameter $\rho=5,9804>\chi_{0,05 ; 1}^{2}=3,841$. Lag significant independent variables are independent variables with a significant weighting, but there are no independent variables that are significant with the weighting.
\end{abstract}

Keywords: Poverty, OLS, Spatial Durbin Model

\section{Pendahuluan}

Kemiskinan didefinisikan sebagai ketidakmampuan individu dalam memenuhi kebutuhan dasar minimal untuk layak hidup (BPS dan Depsos, [3]). Tingkat kemiskinan di Kabupaten Gianyar menurut data BPS Kabupaten Gianyar, tercatat bahwa tahun 2008 mencapai 7,32\%, turun 0,62\% dibandingkan kondisi tahun 2010 mencapai 6,70\% penduduk miskin (BPS, [4]). Walaupun persentase kemiskinan turun, masih terdapat beberapa desa yang mempunyai tingkat kemiskinan tinggi di antara desa lainnya di Kabupaten Gianyar yaitu Desa Lodtunduh, Desa Pupuan, Desa Taro, Desa Beresela, dan Desa Bukian (BPMPD, [2]). Beberapa faktor yang memengaruhi kemiskinan, antara lain faktor pendidikan, sumber daya manusia, sumber daya alam, ekonomi, dan lapangan kerja. Setiap rumah tangga di daerah yang berbeda memiliki karakteristik dan faktor pengaruh yang berbeda, sehingga diperlukan identifikasi faktor-faktor yang berpengaruh terhadap kemiskinan dengan memerhatikan pengaruh daerah.

\footnotetext{
${ }^{1}$ Mahasiswa Jurusan Matematika FMIPA Universitas Udayana

${ }^{2,3}$ Staf Pengajar Jurusan Matematika FMIPA Universitas Udayana
} 
Pemodelan yang menggunakan pengaruh daerah dalam melihat pengaruh variabel independen terhadap variabel dependen disebut pemodelan spasial. Ciri dari pemodelan spasial adalah adanya matriks pembobot yang merupakan penanda adanya hubungan antara suatu wilayah dengan wilayah lain. Pemodelan spasial dilakukan dengan proses autoregressive, yaitu ditunjukkan dengan hubungan ketergantungan antar sekumpulan pengamatan atau lokasi (LeSage dan Pace, [5]). Salah satu model spasial autoregressive adalah model spasial Mixed RegressiveAutoregressive (Anselin, [1]), memiliki bentuk persamaan seperti Spatial Autoregressive Model (SAR), dengan pengaruh spasial lag hanya pada variabel dependen. Spatial Durbin Model (SDM) merupakan salah satu jenis dari model tersebut, dikembangkan karena dalam beberapa kasus hubungan dependensi dalam spasial tidak hanya terjadi pada variabel dependen, tetapi juga pada variabel independen sehingga ditambahkan spasial lag $W X$.

SDM pada penelitian ini menganalisis faktor-faktor yang berpengaruh signifikan terhadap kemiskinan dari sudut pandang kewilayahan di Kabupaten Gianyar.

\section{Spatial Durbin Model (SDM)}

Spatial Durbin Model (SDM) merupakan kasus khusus dari SAR dengan menambahkan pengaruh lag pada variabel independen sehingga ditambahkan spasial lag pada model, pembobotan dilakukan pada variabel independen maupun dependen. Bentuk model SDM seperti pada persamaan (1) (Anselin, [1]).

$$
y_{i}=\rho \sum_{j=1}^{n} w_{i j} y_{j}+\beta_{0}+\sum_{k=1}^{l} \beta_{1 k} x_{k i}+\sum_{k=1}^{l} \beta_{2 k} \sum_{j=1}^{n} w_{i j} x_{k j}+\varepsilon_{i}
$$

dengan $k$ menyatakan banyaknya variabel dan $i$ menyatakan amatan ke- $i$.

Dalam bentuk matriks model SDM seperti pada persamaan (2).

$$
y=\rho W_{1} y+\beta_{0}+X \beta_{1}+W X \beta_{2}+\varepsilon .
$$

\section{Metode Penelitian}

Data yang digunakan dalam penelitian ini berupa data sekunder yang diperoleh dari BPS dan Bappeda Kabupaten Gianyar, serta data dari BPMPD Provinsi Bali. Tahapan penelitian diawali dengan mendeskripsikan variabel penelitian dari sudut kewilayahannya dengan peta tematik. Kemudian dilakukan pemodelan variabel persentase rumah tangga miskin dan faktor-faktor memengaruhinya, terdiri dari: mengidentifikasi pola hubungan dengan menggunakan scatterplot dan analisis korelasi, uji dependensi spasial dengan menggunakan statistik uji Moran's I pada setiap variabel dilanjutkan dengan membentuk Moran's scatterplot untuk mengetahui penyebaran antarlokasi, kemudian melakukan pemodelan OLS, terdiri dari: melakukan penduga parameter pada variabel independen tehadap variabel dependen serta melakukan uji hipotesis signifikansi parameter, pemeriksaan asumsi residual untuk mengetahui asumsi residual memenuhi identik, independen, dan berdistribusi normal, melakukan uji dependensi spasial menggunakan Moran's I, dan melakukan uji heterogenitas spasial dengan Breusch-Pagan Test pada residual. 
Langkah selanjutnya melakukan pemodelan SDM, terdiri dari: melakukan penduga parameter untuk melihat dependensi lag pada variabel dependen maupun variabel independen, melakukan uji hipotesis signifikansi parameter, membandingkan hasil analisis metode OLS dengan metode SDM dengan melakukan pemilihan model terbaik, menggunakan kriteria AICc (Akaike's Information Criteria corrected), dan terakhir interpretasi model.

\section{Hasil dan Pembahasan}

Tahun 2011 BPMPD Provinsi Bali mencatat terdapat 103,516 rumah tangga di Kabupaten Gianyar, dengan 25,00\% atau 25,877 rumah tangga miskin, angka tersebut masih jauh dari target yang diharapkan, $0 \%$ kasus kemiskinan.

Persentase desa yang memiliki rumah tangga miskin sebesar $73,18 \%$ terletak di Desa Beresela, Kecamatan Payangan dan persentase desa yang memiliki rumah tangga miskin sebesar 2,18\% terletak di Desa Batubulan, Kecamatan Sukawati.

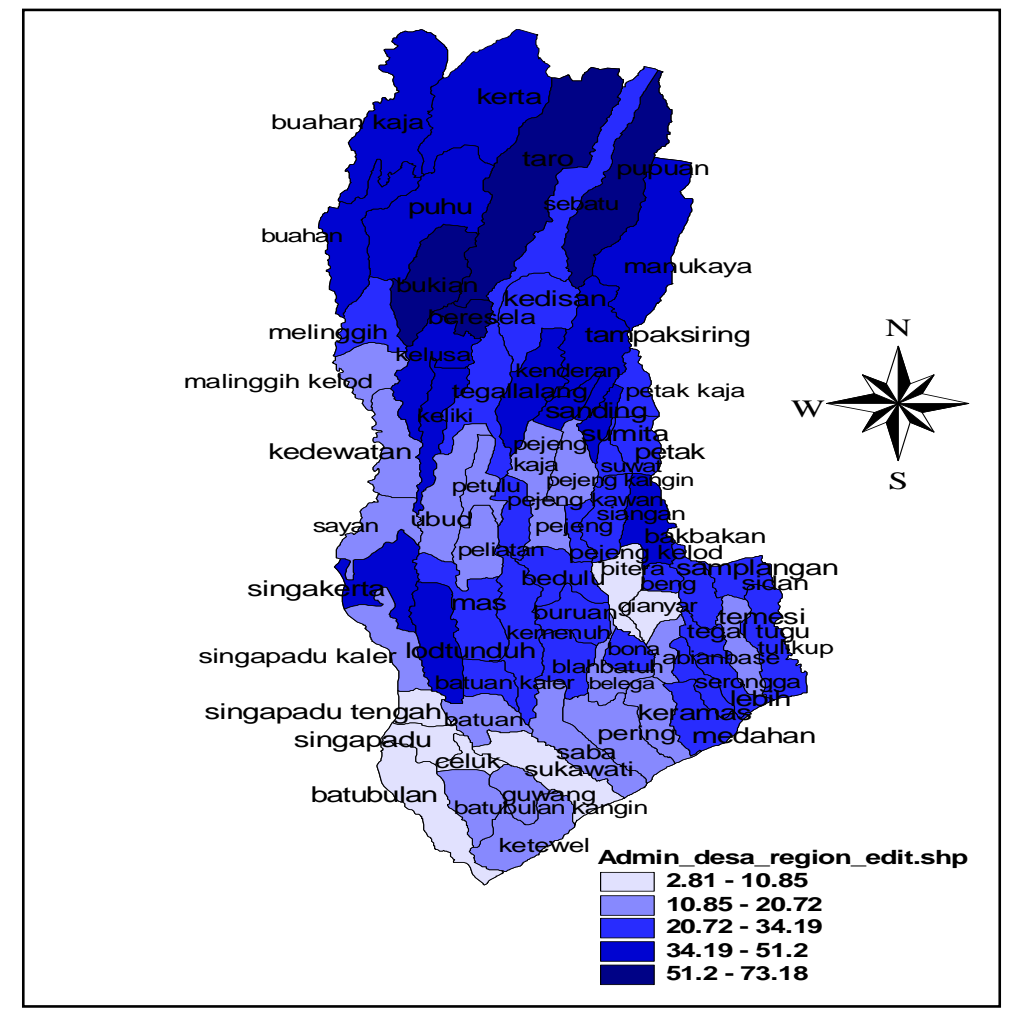

Gambar 1. Penyebaran Persentase Rumah Tangga Miskin

Seperti tampak pada Gambar 1, dapat dilihat pola penyebaran rumah tangga miskin setiap desa di Kabupaten Gianyar. Berdasarkan Gambar 1, dapat diketahui warna lokasi yang semakin gelap, mengidentifikasikan semakin tinggi persentase rumah tangga miskin di lokasi tersebut. Terlihat bahwa desa dengan kategori persentase rumah tangga miskin sangat tinggi $(51,2 \%-73,18 \%)$ terdapat di Desa Bukian, Desa Beresela, Desa Taro, dan Desa Pupuan. 
Kategori rumah tangga miskin sangat rendah (2,81\%-10,85\%) terdapat di Desa Celuk, Desa Sukawati, Desa Singapadu, Desa Singapadu Tengah, Desa Batubulan, Kelurahan Gianyar, dan Kelurahan Bitera.

\section{Nilai Moran's I}

Uji dependensi spasial dilakukan untuk mengidentifikasi apakah ada hubungan antarlokasi terhadap masing-masing variabel dengan Moran's I.

Hipotesis yang digunakan adalah:

$H_{0}: \mathrm{I}_{M}=0$ (tidak ada dependensi antarlokasi)

$H_{1}: \mathrm{I}_{M} \neq 0$ (ada dependensi antarlokasi)

pengambilan keputusan dilakukan jika $\left|Z_{\text {hitung }}\right|>Z_{\alpha} / 2$ maka tolak $H_{0}$.

Tabel 1. Pengujian Moran's I

\begin{tabular}{|l|l|c|c|}
\hline Kode & \multicolumn{1}{|c|}{ Variabel } & Moran's I & $\left|\boldsymbol{Z}_{\text {hit }}\right|$ \\
\hline$Y$ & persentase rumah tangga miskin & 0,447 & 1,378 \\
\hline$X_{1}$ & persentase jumlah sarana pelayanan kesehatan & 0,325 & 0,672 \\
\hline$X_{2}$ & persentase jumlah sarana sekolah & 0,037 & 0,623 \\
\hline$X_{3}$ & persentase penduduk yang bekerja di sektor pertanian & 0,281 & $2,156^{*}$ \\
\hline$X_{4}$ & persentase penduduk yang bekerja di sektor formal & 0,423 & 0,931 \\
\hline$X_{5}$ & persentase penduduk yang bekerja di sektor informal & 0,114 & 0,194 \\
\hline$X_{6}$ & persentase rumah tangga yang menggunakan TV & 0,170 & 1,359 \\
\hline$X_{7}$ & persentase rumah tangga yang menggunakan air bersih & 0,482 & 0,048 \\
\hline$X_{8}$ & persentase penduduk yang belum tamat SD & 0,314 & 0,726 \\
\hline$X_{9}$ & pendapatan rutin desa & 0,375 & $2,507^{*}$ \\
\hline$X_{10}$ & jarak desa dari pusat Kabupaten Gianyar & 0,896 & 1,296 \\
\hline
\end{tabular}

*) signifikan pada $\alpha=5 \% ; Z_{0,025}=1,96$

Berdasarkan hasil pengujian $\left|Z_{\text {hitung }}\right|>Z_{\alpha / 2}$ pada Tabel 1, maka pengambilan keputusan adalah tolak $H_{0}$ atau terdapat dependensi setiap desa pada dua variabel, yaitu persentase penduduk yang bekerja di sektor pertanian $\left(X_{3}\right)$ dan pendapatan rutin desa $\left(X_{9}\right)$. Kedua variabel tersebut memiliki nilai Moran's I lebih besar dari $I_{M O}=-0,0145$ menunjukkan pola data mengelompok dan memiliki kesamaan karakteristik pada lokasi yang berdekatan. Variabel persentase jumlah sarana sekolah $\left(X_{2}\right)$, memiliki pola yang menyebar ditunjukkan dengan nilai Moran's I mendekati nol sehingga setiap desa memiliki karakteristik berbeda.

\section{Pemodelan Ordinary Least Square (OLS) dan Pemodelan Spatial Durbin (SDM)}

Hasil pengujian serentak dapat dilihat pada Tabel 2, menghasilkan nilai $F_{\text {hitung }}>F_{0,05 ; 2 ; 67}$ sehingga keputusan diambil adalah tolak $H_{0}$, ini berarti variabel independen secara serentak berpengaruh terhadap variabel dependen. 
Tabel 2. Penduga Parameter Tiga Variabel yang Signifikan dengan OLS

\begin{tabular}{|clcl|}
\hline Parameter & Penduga/Estimasi & $\left|t_{\text {hitung }}\right|$ & VIF \\
\hline$\beta_{0}$ & 24,488 & 5,30 & \\
$\beta_{3}$ & 0,30576 & $3,24^{*}$ & 1,2 \\
$\beta_{9}$ & $-0,00002501$ & $-3,04^{*}$ & 1,3 \\
$\beta_{10}$ & 0,5642 & $2,04^{*}$ & 1,3 \\
\hline R-square & & $38,8 \%$ \\
$F_{\text {hitung }}$ & & 21,20 \\
AICc & & 522,424 \\
\hline
\end{tabular}

*) signifikan pada $\alpha=5 \% ; t_{0,025 ; 67}=1,996 ; F_{0,05 ; 2 ; 67}=3,13$

Hasil uji parsial seperti pada Tabel 2, dengan menggunakan metode OLS ( $\left.\left|t_{\text {hitung }}\right|>t_{0,025 ; 59}\right)$, diperoleh variabel yang signifikan yaitu persentase penduduk yang bekerja di sektor pertanian $\left(X_{3}\right)$, pendapatan rutin desa $\left(X_{9}\right)$, dan jarak desa dari pusat Kabupaten Gianyar $\left(X_{10}\right)$. Model yang terbentuk dari OLS adalah:

$$
\hat{y}=24,5+0,306 X_{3}-0,000025 X_{9}+0,564 X_{10}
$$

Hasil estimasi pemodelan SDM dapat dilihat pada Tabel 3, bahwa terdapat dependensi lag pada variabel dependen maupun variabel independen. Hal tersebut ditunjukkan oleh parameter $\rho$, yaitu lag variabel dependen yang berpengaruh signifikan. Lag variabel independen yang signifikan adalah variabel-variabel independen dengan pembobot yang berpengaruh signifikan. Namun, pada Tabel 3, menjelaskan tidak terdapat variabel independen yang berpengaruh signifikan dengan adanya pembobot, dikarenakan hasil uji Wald $<\chi_{0,05 ; 1}^{2}=3,841$. Variabel yang berpengaruh signifikan ketika tanpa pembobot antara lain persentase penduduk yang bekerja di sektor pertanian $\left(X_{3}\right)$ dan pendapatan rutin desa $\left(X_{9}\right)$.

Tabel 3. Penduga Parameter dengan Metode SDM

\begin{tabular}{|c|lll|}
\hline Parameter & \multicolumn{1}{|c}{ Variabel } & \multicolumn{1}{c|}{ Penduga } & \multicolumn{1}{c|}{ Wald } \\
\hline$\beta_{0}$ & intersep & 0,0161 & 0,0382 \\
$\beta_{13}$ & persentase penduduk yang bekerja di sektor pertanian & 0,2629 & $8,2698^{*}$ \\
$\beta_{19}$ & pendapatan rutin desa & $-0,2487$ & $6,5131^{*}$ \\
$\beta_{110}$ & jarak desa dari pusat Kabupaten Gianyar & 0,3705 & 2,5447 \\
\hline$\beta_{23}$ & persentase penduduk yang bekerja di sektor pertanian & 0,0088 & 0,0539 \\
$\beta_{29}$ & pendapatan rutin desa & $-0,0326$ & 0,7727 \\
$\beta_{210}$ & jarak desa dari pusat Kabupaten Gianyar & $-0,0720$ & 1,7866 \\
$\rho$ & persentase rumah tangga miskin & 0,0710 & $5,9804^{*}$ \\
\hline R-square & & & $52,95 \% 3$ \\
AICc & & & 37,377 \\
\hline
\end{tabular}

*) signifikan pada $\chi_{0,05 ; 1}^{2}=3,841$

Model yang terbentuk dari SDM adalah:

$$
\begin{gathered}
\hat{y}=0,0710 W_{1} y+0,0161 J+0,2629 X_{3}-0,2487 X_{9}+0,3705 X_{10}+ \\
0,0088 W_{1} X_{3}-0,0326 W_{1} X_{9}-0,0720 W_{1} X_{10} .
\end{gathered}
$$




\section{Kesimpulan}

Lag variabel dependen signifikan ditunjukkan oleh parameter $\rho$ yang lebih besar dari $\chi_{0,05 ; 1}^{2}=3,841$. Tidak adanya lag variabel independen dengan pembobot yang signifikan menyebabkan hasil estimasi parameter menggunakan SDM menjadi tidak signifikan akan tetapi pada identifikasi nilai Moran's I mengidentifikasikan adanya dependensi spasial pada variabel independen.

\section{Daftar Pustaka}

[1] Anselin, L. 1988. Spatial Econometrics: Methods and Models. Kluwer Academic Publishers. Netherlands.

[2] BPMPD (Badan Pemberdayaan Masyarakat dan Pemerintahan Desa) Provinsi Bali. 2011. Pendataan Program Perlindungan Sosial (PPLS). BPMPD Bali. Bali.

[3] BPS (Badan Pusat Statistik) dan Depsos (Departemen Sosial). 2002. Penduduk Fakir Miskin Indonesia 2002. Jakarta: BPS.

[4] BPS (Badan Pusat Statistik) Kabupaten Gianyar. 2012. Statistik Daerah Kabupaten Gianyar. Badan Pusat Statistik Kabupaten Gianyar. Gianyar.

[5] LeSage dan Pace, R. K. 2009. Introduction to Spatial Econometrics. CRC Press. Boca Ration. 